\title{
Ensaio
}

\section{Ensaio crítico sobre a cooperação internacional em saúde DOI: 10.3395/reciis.v4i1.350pt}

\section{Paulo Marchiori Buss}

Professor e pesquisador da Escola Nacional de Saúde Pública da Fundação Oswaldo Cruz (ENSP-Fiocruz); Diretor do Centro de Relações Internacionais em Saúde (CRIS), Fiocruz; ex-Presidente da Fiocruz; Membro Titular da Academia Nacional de Medicina buss@fiocruz.br

\section{José Roberto Ferreira}

Doutor Honoris Causa da ENSP-Fiocruz; Chefe da Divisão de Cooperação Internacional do CRIS, Fiocruz; ex-Diretor da Divisão de Recursos Humanos da Organização Pan-americana de Saúde.

ferreirj@fiocruz.br

\section{Resumo}

Este ensaio discute as necessidades de cooperação internacional em saúde, o modelo dominante da cooperação neste campo, algumas alternativas ao mesmo - que inclui a cooperação Sul-Sul - e prognósticos para o cenário cooperação internacional, considerada parte da diplomacia da saúde.

\section{Palavras-chave}

cooperação internacional em saúde; cooperação Sul-Sul; diplomacia da saúde; saúde global

\section{Necessidades de cooperação internacional em saúde}

O 'breve' século XX, como foi definido por Eric Hobsbawm (1995), foi marcado por importantes avanços econômicos, sociais e técnico-científicos, que melhoraram a qualidade de vida e as condições de saúde de milhares de pessoas em todo o mundo. Contudo, como 'era dos extremos', na mesma definição de Hobsbawm, o processo de globalização vigente também tem criado grandes disparidades internacionais e produzido enormes problemas sociais e de saúde, particularmente nos países mais excluídos dos circuitos centrais da economia global (ILO, 2004; BUSS, 2007). Neste início de século XXI, as condições declinantes da saúde de grandes parcelas da população em diversos países do mundo (WHO/AFRO, 2006; WHO, 2009a), a inseguridade alimentar (FAO, 2009) e, evidentemente, as consequências das mudanças climáticas (IPCC, 2007), têm sido motivo da atenção da chamada comunidade internacional.

Nos países e regiões acima mencionados, verifica-se uma 'dupla carga de enfermidades', isto é, o convívio de doenças transmissíveis epidêmicas, emergentes, reemergentes e negligenciadas - como as 'três grandes' (HIV/aids, malária e tuberculose) - com doenças crônicas não-transmissíveis, entre as quais doenças cardiovasculares, diabetes, obesidade, neoplasias e doenças mentais. Além disso, pobreza, fome, subnutrição e atenção insatisfatória à maternidade, infância e idosos são responsáveis pelas elevadas mortalidades geral, materna e de menores de 5 anos, bem como pela baixa expectativa de vida ao nascer (WHO, 2009a). Iniquidades nas condições de saúde e no acesso aos cuidados de saúde são encontradas tanto entre países, quanto no interior dos mesmos (WHO, 2009a). De outro lado, há um crescente consenso de que, sem populações saudáveis, não haverá desenvolvimento.

Os chamados países de renda baixa e média - alguns dos mais pobres do mundo e nos quais são prevalentes as condições de saúde como as que mencionamos acima - apresentam sérias limitações na sua 'governança' e têm baixa capacidade de formular e implementar políticas sociais e de saúde capazes de enfrentar as necessidades de suas populações. Seus sistemas de saúde são geralmente frágeis, fragmentados, sub-financiados e faltam neles os recursos tecnológicos básicos para oferecer assistência à saúde e medidas de saúde pública adequadas às necessidades da população (WHO, 2008a).

De maneira geral, os profissionais de saúde disponíveis são escassos, mal capacitados e mal remunerados (WHO, 2006), o que se agrava com a migração desses profissionais, especialmente dos países em desenvolvimento para os países desenvolvidos. As razões para este brain draining são muitas, 
entre elas a falta de oportunidades e os baixos salários nos países de origem, mas também esquemas de treinamento no exterior, sem garantias de retorno, o que consideramos um dos efeitos mais negativos da 'assistência' internacional.

A questão dos recursos humanos em saúde é tão importante que tem sido levada à atenção da Assembléia Mundial da Saúde (AMS) nos últimos anos, fazendo com que a OMS a estabelecesse como tema para o Relatório Mundial de 2006 (WHO, 2006a). A AMS produziu um pacto global sobre o desenvolvimento dos recursos humanos para a saúde (WHO, 2006b), assim como normatizou a migração dos profissionais (WHO, 2009c) - esta última destinada a bloquear e/ou compensar a 'drenagem de cérebros' dos países em desenvolvimento para os países desenvolvidos.

Em síntese, os sistemas de saúde da maioria dos países pobres são incapazes de enfrentar as necessidades de suas populações, as doenças prevalentes, seus principais fatores de risco e as péssimas condições de vida que afetam a saúde, o que os coloca em situação de grande dependência da ajuda internacional, crucial tanto para o desenvolvimento quanto para a melhoria das condições de vida e saúde de suas populações.

As causas de tais questões - más condições de vida e de saúde e baixa capacidade de resposta por parte dos países em desenvolvimento - não são fruto do acaso. Como apontam diversos relatórios internacionais e autores, os determinantes sociais e econômicos da saúde (WHO, 2008b) e o fenômeno da globalização injusta, com a pobreza e a iniquidade entre as nações e no interior das mesmas, como pano de fundo (ILO, 2004; BUSS, 2007), estão na raiz da situação.

Com diversas iniciativas, atendendo interesses muitas vezes contraditórios, as Nações Unidas, as agências de cooperação dos países mais desenvolvidos do mundo e a filantropia internacional tratam de responder àquelas preocupações e têm colocado a saúde como prioridade na agenda da cooperação internacional e dos programas de ajuda para o desenvolvimento.

\section{O modelo dominante de cooperação internacional em saúde}

O setor saúde tem sido um foco importante da cooperação internacional e da ajuda externa, que tem sido propiciada segundo interesses, motivações e estratégias muito variadas, por inúmeras agências multilaterais (as próprias Nações Unidas, através dos Objetivos de Desenvolvimento do Milênio e suas agências setoriais como OMS, Unicef, PNUD e outras), governos de países desenvolvidos (EUA e Canadá,
União Européia e países europeus, países nórdicos e Japão, entre outros) ou de países emergentes (caso do Brasil), assim como ONG e outras instituições e iniciativas, mesclando diversos atores antes mencionados que atuam no cenário global (a exemplo da GAVI, entre outras).

Embora munidos das melhores intenções em ajudar as populações pobres dos países mais pobres do mundo, com grande frequência tais atores impõem suas próprias visões de mundo, assim como prioridades e objetivos de cooperação predefinidos. Os países beneficiários muitas vezes têm dificuldades em organizar as próprias demandas, devido à falta de coordenação entre seus Ministérios da Saúde, Relações Exteriores e outros parceiros públicos e privados. As consequências são a fragmentação e a baixa eficiência dos recursos disponíveis localmente, já bastante limitados (BUSS, 2007; 2008).

Neste contexto, é preciso estabelecer uma diferenciação entre 'assistência técnica' e 'cooperação técnica'. A primeira se baseia em iniciativas pré-definidas, desenvolvidas unilateralmente por doadores, com baixa ou nenhuma participação dos beneficiários; já a segunda, representa um esforço conjunto que integra doadores e beneficiários em parceria na qual as experiências prévias e as orientações estratégicas são compartilhadas, visando ao planejamento e à execução conjuntas, com a implementação da autonomia do parceiro e a sustentabilidade do processo como um todo.

Provavelmente, os recursos técnicos e financeiros disponíveis para a cooperação internacional em saúde nunca serão suficientes, dadas as enormes necessidades dos países em desenvolvimento. Entretanto, para tornar as coisas piores, no mais das vezes os recursos são aplicados de forma descoordenada, com os doadores apoiando projetos sobrepostos temática ou territorialmente, enquanto diversas áreas críticas permanecem desassistidas.

Um ex-Ministro da Saúde de Moçambique, examinando os processos de cooperação nos seus países, afirmou, em certa ocasião: quando fui nomeado ministro, pensava que fosse o Ministro da Saúde e, como tal, responsável pela saúde do país. Mas ao contrário, descobri que era o ministro dos projetos de saúde executados por estrangeiros.

Uma recente avaliação sobre os efeitos das parcerias globais no campo da saúde em vinte países em desenvolvimento (MCKINSEY \& COMPANY, 2005) chegou à seguinte conclusão:

Infelizmente, os ganhos obtidos pelas Parcerias em Saúde Global (GHPs, Global Health Partnerships) tiveram um custo. A introdução 'vertical' de recursos em sistemas de saúde organizados horizontalmente, 
em um ambiente com recursos restritos, tende a criar duas prováveis consequências para os países beneficiários: 1) os países têm dificuldades para absorver os recursos de GHP porque tais parcerias não oferecem suportes técnicos (ou de outra natureza) adequados à implementação dos programas; e 2) os países ficam sobrecarregados com processos paralelos e duplicados oriundos de várias GHPS, porque muitas vezes elas ignoram processos já implantados nos países. Além disso, as GHPs não têm comunicação adequada e eficiente com os países e parceiros. As comunicações entre GHPs e países costumam ser de 'via única' e a retro-alimentação dos países ao circuito é falho. A comunicação deficiente complica as questões descritas acima (p. 4).

Importante também discutir o financiamento da cooperação internacional, que foi duramente golpeado pela crise econômico-financeira de 2008-2009. Os países mais ricos do mundo comprometeram-se em aplicar em ajuda externa cerca de 0,7\% de seu produto interno bruto até 2015 para atingir os Objetivos do Milênio. Entretanto, esta proporção caiu pela metade nos últimos 40 anos: era de 0,48\% entre 1960 e 1965, hoje é de apenas 0,24\% (OXFAM, 2005). Aquela proporção representa USD 80 por habitante dos países mais ricos, por ano, em programas de ajuda internacional, o que equivale a não mais do que um quinto dos gastos com defesa ou metade dos gastos em subsídios agrícolas (BUSS, 2007).

A propósito, a comparação entre gastos militares e ajuda oficial para o desenvolvimento (ODA) é chocante, conforme mostram os Economistas pela Paz e a Segurança (2009): o gasto militar no mundo, em 2003, foi de USD 956 bilhões, dos quais apenas os Estados Unidos gastou USD 417 bilhões. Para alcançar plenamente os ODM estima-se que seriam necessários não mais do que USD 760 bilhões nos próximos 10 anos, menos portanto do que o mundo gasta com armas em apenas 1 ano. O gasto militar per capita nos Estados Unidos foi de USD 1,217.00 enquanto não passou de USD 46.00 para ajuda externa, dos quais apenas 23\% para os mais necessitados. Ou seja, para cada 25 dólares de gasto militar americano apenas 1 dólar é destinado à ajuda externa, do qual apenas 23 centavos para os mais necessitados. Ademais, a maior parte da ODA dos Estados Unidos destina-se a países estratégicos do ponto de vista militar (atualmente, Afeganistão, Iraque, Israel e Paquistão) (GOSTIN, 2009). Na União Européia os gastos militares foram de USD 358.00 per capita para a defesa e USD 61.00 para a ajuda externa. Stiglitz e Bilmes, economistas e professores em Colúmbia e Harvard, respectivamente, estimam que os gastos americanos apenas com a Guerra do Iraque poderão alcançar mais de USD 2 trilhões (FOLHA ON LINE, março 2008).

Às Nações Unidas, as críticas não são menores. Apontada como ineficiente, o sistema de agências da ONU, inclusive a Organização Mundial da Saúde, vê seu orçamento regular - propiciado pela contribuição obrigatória dos Estadosmembros - estagnar, crescendo apenas os recursos financeiros com finalidade específica, apontada diretamente pelos doadores. No caso da OMS, cerca de 60\% do orçamento provém agora de tais contribuições voluntárias (dos próprios países, fundações filantrópicas e empresas privadas), deixando o Conselho Executivo e o Secretariado da OMS com uma margem de manobra programática bastante pequena. Temendo ver estas contribuições ainda mais reduzidas, o Secretariado faz todo o esforço para que se evitem conflitos com doadores poderosos ou que seus interesses sejam contrariados. O crescimento das contribuições voluntárias, em detrimento das obrigatórias (que reforçariam o orçamento regular e, portanto, os programas institucionais de cooperação multilateral) representa possivelmente uma reação de desconfiança dos países-membros com a capacidade de implementação de projetos de cooperação por parte da OMS. Se não chega a tanto, trata-se, no mínimo, de uma deformação do processo de cooperação multilateral, que necessariamente deverá ser revisto em anos vindouros, conforme reconhecem os projetos de reforma em implementação no interior da própria ONU e OMS (ver adiante).

Finalmente, como bem resumem Birn et al. (2009: 6263), a maior parte das atividades em saúde internacional não é compartilhada entre nações 'equivalentes'; elas refletem a ordem política e econômica internacional, na qual a 'assistência' internacional é 'provida' pelas nações ricas e industrializadas e 'recebida' pelos países pobres e subdesenvolvidos. (...) A assistência internacional reflete as relações geopolíticas e reproduz os desequilíbrios de poder e recursos. Isto significa que, como ação integrante e fundamental nas relações internacionais, a cooperação internacional reproduz as relações de poder instaladas no mundo globalizado e só será efetivamente modificada se também se alterarem as estruturas e regras da governança global em saúde.

Face à situação da cooperação internacional em saúde, sumariamente descrita acima, e insatisfeitos com os resultados obtidos em relação ao desenvolvimento e à saúde, diversos atores envolvidos em saúde global passaram 
a buscar alternativas ao modelo dominante, algumas das quais serão discutidas a seguir.

\section{Alternativas ao modelo dominante}

As críticas à governança global em saúde são pertinentes. Em todo o espectro das relações internacionais em saúde - inclusive da cooperação técnica - predominam as visões, políticas e práticas dos governos ou das organizações nãogovernamentais, filantrópicas e empresariais dos países mais poderosos economicamente e que também ocupam a maior parte dos cargos das organizações multilaterais e das parcerias globais que dispõem de maior poder político e/ou econômico ou nelas impõem suas orientações políticas.

Muitos autores e organizações debruçaram-se criticamente sobre a governança global em saúde (GARRET, 2007; BLOOM, 2007; BIRN et al., 2009; GOSTIN \& MOK, 2009), a quem remetemos o leitor interessado já que, não sendo foco central deste artigo, não será aqui desenvolvida senão, quando necessário, em aspectos pertinentes à cooperação internacional em saúde.

Visando formular um processo mais adequado de cooperação com países em desenvolvimento, diversas alternativas - que de uma forma ou outra questionam as práticas tradicionais e prevalentes de cooperação - devem ser tomadas em consideração. Este processo deveria orientar-se por:

- mudar a estratégia de cooperação, calcada em programas baseados em uma única orientação global dos doadores, para uma cooperação compartilhada, orientada pelo planejamento estratégico centrado na realidade do país parceiro;

- passar de programas de ajuda 'verticais' (intervenções com enfoque em doenças ou situações e problemas particulares) para o enfoque 'horizontal', isto é, que foca o desenvolvimento integral dos sistemas de saúde. Os programas verticais não contribuem para o fortalecimento do sistema como um todo; ao contrário, levam à fragmentação e à debilidade do mesmo, seja pelo recrutamento do melhor pessoal disponível no país, seja por se concentrarem em certas áreas, abandonando outras áreas prioritárias;

- dar ênfase ao longo prazo, ao invés de concentrarse exclusivamente nas necessidades de curto prazo. Isto implica no fortalecimento de instituiçõesestruturantes dos sistemas de saúde para que venham a adquirir genuína liderança nos processos nacionais; no desenvolvimento de uma agenda orientada para o futuro; e no equilíbrio entre ações específicas dirigidas a resolver problemas imediatos com a geração de conhecimentos e o desenvolvimento de capacidades institucionais nacionais sustentáveis;

- incorporar amplamente nos programas de cooperação em saúde os determinantes sociais da saúde e as ações inter-setoriais;

- priorizar programas de saúde pública (foco na população) ao invés de programas e atividades focadas estritamente em indivíduos.

Para fomentar a perspectiva da diplomacia da saúde, também é importante associar excelência em saúde com a fortaleza do setor de relações exteriores, em especial no caso da cooperação Sul-Sul. O conceito da 'diplomacia da saúde' (KICKBUSCH et al., 2007; BUSS, 2008) emergiu para tratar dos fatores da saúde que transcendiam as fronteiras nacionais e expunham os países às influências globais. Esta noção também possibilitou uma coordenação melhor e mais coesa entre os setores de saúde e relações exteriores dos governos, não apenas nutrindo a aceitação dos objetivos vinculados à saúde contidos nas Metas de Desenvolvimento do Milênio, como também assegurando a incorporação das mesmas nas plataformas de saúde e desenvolvimento dos países.

As críticas severas às formas vigentes de ajuda para o desenvolvimento propiciada pelos países desenvolvidos e organizações multilaterais, vindas de todos os lados, os levou a realizar o Fórum de Alto Nível para a Efetividade da Ajuda (High-Level Forum on Aid Effectiveness), em 2005, em Paris, para reorientar a ajuda para o desenvolvimento, procurando torná-la mais eficaz, na perspectiva da revisão quinquenal da Declaração do Milênio e dos ODMs (UN, 2000), que ocorreria mais tarde, no mesmo ano. Deste evento, surgiu a 'Declaração de Paris sobre a Efetividade na Ajuda' (Paris Declaration on Aid Effectiveness) (OECD, 2005) que, firmada por centenas de paises e dezenas de instituições globais, inclusive da sociedade civil (OECD, 2009), reitera a necessidade de ampliar a ajuda para o desenvolvimento, mas também melhorar sua eficácia, através das estratégias de:

- Apropriação: os países parceiros beneficiários da ajuda exercem liderança efetiva sobre as suas políticas e estratégias de desenvolvimento e asseguram a coordenação das ações realizadas para tal fim. 
- Alinhamento: os doadores baseiam todo o seu apoio nas estratégias nacionais de desenvolvimento, instituições e procedimentos dos países parceiros beneficiários da ajuda.

- Harmonização: as ações dos doadores nos países são harmonizadas, isto é, coordenadas, nãocompetitivas e complementares, assim como mais transparentes e coletivamente eficazes.

- Gestão centrada em resultados: a tomada de decisões é centrada na obtenção de resultados e os recursos são aplicados de forma coerente com este processo.

- Responsabilização mútua: doadores e países parceiros são mutuamente responsáveis pelos resultados obtidos em matéria de desenvolvimento. Para cada uma destas estratégias foram estabelecidos objetivos para serem alcançados até 2010 e um processo de monitoramento foi estruturado para tal.

Os conceitos e orientações centrais da Declaração de Paris são:

- reforço das estratégias nacionais de desenvolvimento dos países parceiros e dos processos operacionais correspondentes (planejamento, orçamentos e quadros de avaliação de desempenho, por exemplo);

- alinhamento da ajuda com as prioridades, sistemas e procedimentos dos países parceiros e apoio ao reforço das suas capacidades;

- reforço da responsabilidade mútua dos doadores e países parceiros para com os seus cidadãos e parlamentos, no que respeita às suas políticas e estratégias de desenvolvimento, bem como aos resultados obtidos;

- eliminação da duplicação de esforços e racionalização das atividades dos doadores, no sentido de otimizarem o seu rendimento;

- reforma e simplificação das políticas e procedimentos dos doadores, de modo a favorecer a colaboração e o alinhamento progressivo com as prioridades, sistemas e procedimentos dos países parceiros;

- definição de medidas e padrões de desempenho e de responsabilidade para os sistemas dos países parceiros, nos domínios da gestão das finanças públicas, aprovisionamento (procurement), garantias fiduciárias e avaliação ambiental, de conformidade com as boas práticas amplamente aceitas, aplicandoas de forma rápida e generalizada.
Preocupação crescente é também encontrar mecanismos capazes de implementar os princípios constantes da Declaração de Paris. Neste sentido, a chamada 'abordagem setorial ampliada' (sector-wide approach ou SWAP) (CASSELS, 1997; BROWN et al., 2001; HUTTON \& TANNER, 2004) tem sido usada em diversos cenários, como na área da saúde na África (WALDORF, 2007), procurando operacionalizar particularmente os conceitos de apropriação, alinhamento e harmonização. Os SWAP buscam facilitar e reduzir o peso de coordenação e requerimentos de relatórios de acompanhamento e prestação de contas etc. que recai sobre aos governos dos países, devido a proliferação de doadores, com suas múltiplas e diferentes exigências e práticas de gestão. As várias agências parceiras dos países transformam-se numa espécie de 'consórcio de parceiros em saúde', que pactuam pelo uso de procedimentos comuns de planejamento, implementação, monitoramento e informes; além disso, comprometem-se de articular diversos atores envolvidos num assunto específico ou em um território particular do país (BIRN et al., 2009).

Outra iniciativa, a Parceria Internacional para a Saúde (INTERNATIONAL HEALTH PARTNERSHIP, 2010), lançada em 2007, propõe a harmonização de paises doadores e outros parceiros internacionais em torno de estratégias nacionais em saúde lideradas pelos países parceiros, utilizando os princípios da Declaração de Paris e a Agenda de Acra. Tal iniciativa encontra-se em desenvolvimento em 15 paises da África e 2 países da Ásia.

A importante Declaração de Paris e as adesões de inúmeros países e organizações às suas propostas, fariam supor um aumento na ajuda externa para o desenvolvimento e práticas mais adequadas, com repercussões positivas sobre a 'jóia da coroa' da cooperação internacional, isto é, o grande projeto mundial de desenvolvimento traçado pelas Nações Unidas para o século XXI: os Objetivos de Desenvolvimento do Milênio, resultantes da Cúpula do Milênio, realizada no ano 2000, em Nova York (UN, 2000).

Entretanto, as conclusões dos dois últimos Relatórios sobre os ODM em geral, incluindo o objetivo 8, são muito preocupantes. O Informe de 2007 (UN, 2007) afirma que a ajuda para o desenvolvimento vem decrescendo, apesar da renovação (retórica) dos compromissos dos países doadores; que os doadores se comprometeram a dobrar suas ajudas para a África, embora pouco tenha sido feito até o momento; e que o acesso preferencial aos mercados de países desenvolvidos reduziu-se para a maioria dos países em desenvolvimento. Já o Relatório de 2008 (UN, 2008a) 
acrescenta que a ajuda para o desenvolvimento caiu pelo segundo ano consecutivo, afetando os compromissos para 2010; que os subsídios agrícolas domésticos dos países ricos superam em muito o dinheiro usado na ajuda para o desenvolvimento; e que a baixa disponibilidade e os preços elevados são barreiras para o acesso a medicamentos essenciais em países em desenvolvimento. Em 2008, as Nações Unidas realizaram em Nova York o Evento de Alto Nível sobre ODM, no qual se registram as preocupações com a lentidão do progresso na direção do alcance dos objetivos em diversos países, particularmente nos mais pobres e, apesar das constantes reiterações, a falha no financiamento por parte dos países desenvolvidos (UN, 2008c).

Um informe do Banco Mundial e FMI também alerta que a maioria dos países encontra-se distante de alcançar as Metas do Milênio. Embora boa parte do mundo venha conseguindo reduzir a pobreza extrema, as perspectivas de redução das mortalidades infantil e materna apresentam maiores dificuldades. $\mathrm{O}$ mesmo ocorre com a universalização da escolaridade primária, bem como com objetivos de nutrição e saneamento básico. O Informe também alerta para as relações entre ambiente e desenvolvimento e exorta por ações urgentes quanto às mudanças climáticas. Para construir sobre os ganhos obtidos com tanta dificuldade, os países em desenvolvimento precisam de suporte para tratar das conexões entre crescimento, desenvolvimento e sustentabilidade ambiental (WORLD BANK, 2008).

Em setembro de 2008, realizou-se em Acra, Gana, o Fórum de Alto Nível de Acra sobre a Efetividade da Ajuda, que veio a gerar a 'Agenda para a Ação de Acra' (UN, 2008b), a qual reitera a Declaração de Paris e reforça a decisão de reduzir a onerosa fragmentação da ajuda. Logo depois, em dezembro de 2008, em Doha, realizou-se a Conferência sobre o Financiamento para o Desenvolvimento, que produziu a 'Declaração de Doha sobre o Financiamento para o Desenvolvimento' (UN, 2008b), que reafirmou (pelo menos 'no papel') a disposição dos países desenvolvidos em comprometer $0.7 \%$ dos respectivos PIB para a ajuda externa a países em desenvolvimento até 2015. Ambos documentos fazem referências específicas e atribuem ênfase especial à cooperação com a África, região que apresenta a pior evolução quanto à execução das metas dos ODM (MDG AFRICA STEERING COMMITTEE, 2008).

As próprias Nações Unidas, criticadas pela descoordenação de suas ações nos países, inclusive no campo da saúde, lançou a iniciativa de articular o trabalho de suas diversas agências nos países, sob a coordenação do PNUD.
Com respeito especificamente à saúde, um dos primeiros movimentos realizados entre países foi a 'Iniciativa Política Externa e Saúde Global' lançada pelos Ministérios das Relações Exteriores da África do Sul, Brasil, França, Indonésia, Noruega, Senegal e Tailândia (2007), que resulta na Declaração de Oslo, chamando a atenção para a prioridade que deveria ser dada à saúde na política externa de todos os países. Em resposta a este chamado internacional, realizado por países importantes de diversos continentes, a Assembléia Geral das Nações Unidas, por ocasião da 63a. Sessão (2008), adotou a Resolução 63/33 sobre Saúde Global e Política Externa, reconhecendo a estreita relação entre ambas as áreas e determinando que o Conselho Econômico e Social (ECOSOC), na sua sessão de julho de 2009, tratasse do 'Cumprimento dos objetivos e compromissos pactuados internacionalmente com relação à saúde pública global', além de pedir uma maior coordenação dentro do sistema das Nações Unidas no campo da saúde.

A Declaração Ministerial sobre Saúde Pública Global, um longo documento resultante do Segmento de Alto Nível 2009 do ECOSOC (UN/ECOSOC, 2009), realizado em Genebra, enuncia uma ampla agenda para a ação de governos, órgãos das Nações Unidas e da sociedade civil mundial em torno da saúde global, que passam a ser motivo de entendimentos ulteriores entre os Estados-membros das Nações Unidas, seja na Assembléia Geral da ONU, seja no âmbito da OMS.

Por outro lado, no âmbito doméstico da OMS e seus Escritórios Regionais, foi lançada a Política de Cooperação Centrada nos Países da OMS (WHO, 2010), que reúne os seguintes elementos:

- clara definição das estratégias de cooperação em saúde nos países, desenvolvidas em estreita consulta com as autoridades sanitárias nacionais (ASN);

- dotar as Representações da OMS nos países com pessoal adequado à consecução das estratégias de cooperação consensuadas com os mesmos;

- apoio programático e técnico coerente às Representações nos países, por parte das Oficinas Regionais (como a OPS) e da sede (em Genebra);

- garantir um funcionamento administrativo eficaz das Representações nos países para facilitar a consecução dos objetivos consensuados com a ASN;

- desenvolver informação e gestão do conhecimento desde os países e para os mesmos;

- colaborar com organizações do sistema das Nações Unidas e com associados para o desenvolvimento. 
Os resultados destes movimentos no interior das Nações Unidas ainda estão por vir e devem ser acompanhados com atenção pelos atores interessados em saúde global e diplomacia da saúde.

Com a ampliação da presença dos temas Saúde Global e Diplomacia da Saúde na agenda internacional, diversas instituições acadêmicas do mundo têm organizado centros de pesquisa e formação de recursos humanos dedicados à saúde global, relações internacionais e diplomacia da saúde. Um exemplo, no plano nacional, foi dado recentemente pela Fundação Oswaldo Cruz, que criou, em janeiro de 2009, o Centro de Relações Internacionais em Saúde (CRIS) (FIOCRUZ, 2010), vinculado à Presidência da Instituição, com o objetivo de dar maior organicidade à já ampla função de cooperação internacional em saúde desenvolvido pela Fiocruz, em estreito alinhamento com a política externa brasileira, que confere grande ênfase na cooperação para o desenvolvimento, nos campos sociais, nos quais se destaca a saúde. Já no plano internacional, organizam-se alianças acadêmicas, como o Global Health Education Consortium (2010), o Consórcio de Universidades para Saúde Global (2010) e o Consortium for Global Health Diplomacy (2010). Tal movimento tende a crescer no mundo e no Brasil, na medida em que a amizade e a solidariedade internacional superarem a mera competição, muitas vezes predatória, entre as nações.

Em pesquisa em saúde, além do trabalho histórico do TDR (2010) no fomento à investigação e inovação em moléstias infecciosas, encontra-se uma iniciativa mais recente, o Global Forum for Health Research (2010), organização internacional independente, voltada para "o fomento da pesquisa e inovação para a saúde e a equidade em saúde, dirigida à populações pobres e excluídas do mundo".

Neste específico campo, Rottingen et al. (2009) propugnaram recentemente a racionalização da arquitetura global da pesquisa em saúde, com o enxugamento e fusão das inúmeras organizações e iniciativas sediadas em Genebra.

\section{Uma alternativa diferente: a cooperação Sul-Sul}

A responsabilidade pelo desenvolvimento do Sul compete ao Sul, e está nas mãos das pessoas e instituições do Sul. Julius Nyerere (1990)

O conceito e as práticas da 'Cooperação Sul-Sul', também conhecida como 'cooperação horizontal', surgiram fundamentalmente nas esferas política e econômica durante os anos de Guerra Fria. No campo político, a partir da Conferência de Bandung (1955), os países do então chamado 'Terceiro Mundo' buscaram unir-se no chamado 'Movimento dos Não-Alinhados' para fazer frente à bipolaridade, manter-se equidistantes em relação aos blocos liderados por Estados Unidos e União Soviética e negociar o estabelecimento de uma ordem econômica mais favorável. Nesse momento, multiplicavam-se os Estados independentes na África e Ásia, após anos de exploração colonial. A maior parte deles padecia de severa desorganização social, política e econômica decorrente de anos de luta pela autonomia e/ou conflitos étnicos localizados. A busca de cooperação entre os países do sul, buscando soluções a problemas similares recebe também a adesão de algumas nações latino-americanas.

Em 1964, ao final da primeira sessão da Conferência das Nações Unidas para o Comércio e o Desenvolvimento (UNCTAD) 77 países em desenvolvimento firmaram a Declaração que criou o Grupo dos 77. Hoje composto de 130 países, reunindo-se anualmente e atuando de forma concertada em fora internacionais, tem sido ator importante na cooperação Sul-Sul, ainda que principalmente no domínio econômico, como demonstram suas Declarações anuais, mas também em outros domínios, como mostram a Declaração da Cúpula do Sul e o Plano de Ação de Havana (2000), o Consenso de Teerã sobre a Cooperação Sul-Sul (2001), a Declaração de Dubai sobre C\&T no Sul (2002), a Declaração e o Marco de Referência de Marrakech sobre Cooperação Sul-Sul (2003), e, finalmente, a Plataforma de Desenvolvimento para o Sul, com seu conjunto de princípios sobre a cooperação Sul-Sul, e o lançamento do Fundo do Sul para o Desenvolvimento e a Assistência Humanitária (2008) (G77, 2010).

Em assuntos econômicos propriamente ditos, a cooperação Sul-Sul voltava-se ao estímulo aos intercâmbios comerciais inter-hemisféricos, assim como ao compartilhamento de tecnologias de produção. Mais recentemente, com o fim da bipolaridade e as mudanças ocorridas no regime internacional de desenvolvimento, assim como o foco colocado sobre o desenvolvimento humano e sobre a erradicação da pobreza, verifica-se o fortalecimento da cooperação Sul-Sul agora no âmbito social.

Aliás, foi atendendo às reivindicações dos países do sul - para que a cooperação ultrapassasse o sentido de uma ajuda vinculada a interesses político-estratégicos e passasse a ser uma fonte de trocas e interesses mútuos, 
enriquecendo e capacitando todos os entes envolvidos que as Nações Unidas reviram o conceito de assistência técnica e o substituiram pelo termo cooperação técnica (Resolução 1383B, Assembléia Geral da ONU de 1959).

Há cerca de 30 anos, em 1978, no contexto da descolonização de nações, predominantemente da África e algumas da Ásia e Caribe, foi realizada a Conferência das Nações Unidas sobre Cooperação Técnica entre Países em Desenvolvimento (CTPD), cujas recomendações foram aprovadas pelos 138 Estados nacionais participantes, na forma do 'Plano de Ação de Buenos Aires para Promover e Implementar a Cooperação Técnica entre Países em Desenvolvimento', marco na história da cooperação internacional por se ter constituindo na base da autonomia da cooperação externa entre países em desenvolvimento (UNDP, 1978).

Como decorrência, a Unidade Especial para a Cooperação Sul-Sul (Special Unit for South-South Cooperation [SU/ SSC]), foi estabelecida pela Assembléia Geral das Nações Unidas também em 1978. Localizada no Programa das Nações Unidas para o Desenvolvimento (PNUD/UNDP), sua missão fundamental é promover, coordenar e apoiar as cooperações Sul-Sul e triangular em bases globais e da própria ONU. A SU/SSC recebe direcionamento político e orientações do/ e funciona como Secretariado do Comitê de Alto Nível (HLC) para a Cooperação Sul-Sul da Assembléia das Nações Unidas.

Em 1983, a Assembléia estabeleceu o Fundo Fiduciário Pérez Guerrero, gerenciado pela SU/SSC, com o propósito de apoiar atividades de CTPD do Grupo dos 77, destinado a financiar estudos de pré-investimento e viabilidade e facilitar a implementação de projetos desta natureza.

Em 1987 cria-se a Comissão do Sul (The South Commission), formada por 28 líderes de países do sul, entre os quais os brasileiros Dom Paulo Evaristo Arns e Celso Furtado, para expandir a cooperação Sul-Sul; seu Informe (The South Commision, 1990) torna-se um clássico e uma referência mundial sobre o tema.

Em 1993, o Conselho Econômico e Social das Nações Unidas, em resolução ratificada pela Assembléia Geral, sublinhou que todos os agentes vinculados ao processo de desenvolvimento deveriam dobrar esforços para fazer uso mais amplo do CTPD como o método preferencial no preparo e implementação de projetos e atividades relacionados ao desenvolvimento, superando o uso meramente marginal feito até então.

Na $10^{a}$ Sessão do Comitê de Alto Nível das Nações Unidas sobre CTPD, em 1997, foi assinalado que, para a integral otimização da CTPD, era necessário contribuir para o desenvolvimento de políticas e procedimentos institucionais que gerassem recomendações não só para os países em desenvolvimento incorporarem CTPD como elemento central de suas estratégias nacionais de desenvolvimento, mas também para dotar as instâncias relativas ao CTPD nacional e pontos focais dos recursos humanos e financeiros essenciais para seu funcionamento efetivo. Foi também recomendado que o financiamento para a CTPD fosse substancialmente aumentado pelos próprios países em desenvolvimento, assim como pelos países doadores e agências multilaterais.

A queda do muro de Berlim e a subsequente falência do mundo unipolar representado pelo poder imperial dos Estados Unidos, responsável pela crise sem precedentes do capitalismo global desde 1930, assim como o crescimento das economias emergentes e o consequente poder político, estimulou o florescimento de um mundo multipolar, no qual também decola a Cooperação Sul-Sul. Um sinal expressivo dessa situação, assumida globalmente pela comunidade internacional, é a Conferência de Alto Nível das Nações Unidas sobre Cooperação Sul-Sul, realizada em dezembro de 2009, em Nairobi, Quênia, com o tema 'Promoção da Cooperação Sul-Sul para o Desenvolvimento', cujos documentos, debates e resultados podem ser acessados no site da conferência (UN Conference on South-South Cooperation, 2009).

Segundo diversos analistas, cresce de importância a cooperação Sul-Sul em tempos em que proliferam as barreiras comerciais discriminatórias, diminui a assistência ao desenvolvimento devido à crise econômico-financeira, aumenta a dívida externa dos países pobres e caem os preços de algumas matérias-primas. Neste contexto, os países em desenvolvimento do sul, ainda que com as dificuldades inerentes a este processo, buscam fortalecer a unidade e a solidariedade como condição prévia para fortalecer a sua capacidade de negociação em fora internacionais multilaterais

Em estudo divulgado em 2004 (UNDP, 2004), a Unidade Especial para a Cooperação Sul-Sul (PNUD) assinala a importância de fortalecer a assistência mútua 'em um período de rápida globalização'. Impulsionados especialmente pela liderança de Brasil, China e Cuba, aos quais se somou mais recentemente a Índia, a cooperação Sul-Sul vem apresentando diversos exemplos ressaltados no mencionado estudo. É o que vem sendo caracterizado como soft power diplomático, ou seja, a utilização de recursos que não militares ou políticos clássicos nas relações internacionais (NYE, 2008).

O Brasil tem sido muito ativo no apoio a outros países 
em desenvolvimento em matéria de administração pública, saúde, $^{2}$ educação, agricultura, meio ambiente, energia e pequenas empresas, por exemplo. China e Índia contam com importantes programas de capacitação técnica para cidadãos de outras nações em desenvolvimento e para melhorar a capacidade institucional desses países.

Não desatentos ao processo, o G8 responde ao Grupo dos 77, aceitando a proposta de constituição do G20, liderada pelo Brasil. Este jogo ainda está sendo jogado e seu desenlace depende da capacidade de entendimento e construção de consensos entre atores políticos de relevo do lado dos países em desenvolvimento, como Brasil, China e Índia.

Papel fundamental na cooperação Sul-Sul jogam também os arranjos regionais entre países vizinhos do hemisfério. A ASEAN (Associação de Nações do Sudeste da Ásia), a União Africana e o NEPAD (Nova Parceria para o Desenvolvimento da África) no continente africano e a Unasul na América do Sul (UNASUR, 2010) são alguns exemplos de cooperação Sul-Sul nos campos econômico e social ainda em pleno desenvolvimento, mas que devem ser acompanhados com atenção pelo potencial de realizações que oferecem. As soluções Sul-Sul são buscadas até mesmo em comunidades de países ligados por laços culturais, como o idioma, caso da Comunidade de Países de Língua Portuguesa (CPLP, 2010). A propósito, neste mesmo volume os leitores encontrarão um artigo que analisa as experiências de cooperação Sul-Sul em matéria de saúde na CPLP e na Unasul ${ }^{3}$.

\section{Prognósticos para a cooperação internacional em saúde}

Os esforços internacionais se expandiram recentemente a uma série de iniciativas que podem fomentar a cooperação internacional em saúde.

As Metas de Desenvolvimento do Milênio (UN, 2000), o grande pacto mundial em prol do desenvolvimento, firmado pelos governos de todos os Estados-membros das Nações Unidas, são um exemplo muito positivo da resposta internacional à saúde global, posto que três dos seus oito objetivos concentram-se diretamente nos problemas de saúde (mortalidade infantil, saúde materna e doenças transmissíveis específicas, como HIV/aids, malária e tuberculose) e alguns determinantes sociais da saúde como pobreza, fome, educação básica e sustentabilidade ambiental.

Os Relatórios da OMS de 2008 incluem duas outras iniciativas de extrema importância, que estimulam a expansão dos esforços de cooperação internacional: o fortalecimento da Atenção Primária à Saúde, como conceito e prática, 30 anos após a Conferência de Alma-Ata de 1978 (WHO, 2008a) e o grande debate levantado pela Comissão sobre Determinantes Sociais da Saúde (WHO, 2008b), que explicitou um amplo complexo de determinantes sociais da saúde e respostas políticas necessárias para adequadamente enfrentá-los, visando ao fomento das condições de saúde em níveis global e local. Em 2011, o Brasil vai sediar a Conferência Mundial sobre Determinantes Sociais da Saúde, prevista em Resolução da OMS aprovada pela Assembléia Mundial da Saúde em 2009, buscando construir um grande pacto político internacional e uma estratégia global para superar as iniquidades sociais em saúde.

Acordos internacionais globais em saúde, alcançados no âmbito da OMS já nesta primeira década do novo milênio, como a Convenção-Quadro para o Controle do Tabaco (FCTC, 2008) e o Regulamento Sanitário Internacional indicam, apesar da crise de credibilidade da OMS em vários aspectos, a vitalidade e viabilidade de negociações internacionais em temas sanitários cruciais.

Essencial à cooperação internacional, a Declaração de Paris sobre a Eficácia da Ajuda (OCDE, 2005) foi preparada em amplo processo de consulta entre tradicionais doadores e países parceiros, podendo orientar, particularmente pelas estratégias da harmonização e do alinhamento, futuros processos de cooperação em bases mais equitativas, menos onerosas e mais apropriadas aos países em desenvolvimento, particularmente no contexto dos ODM.

Governos, atuando isoladamente ou através de parcerias internacionais, desenvolvem programas e disponibilizam financiamentos para a ajuda para o desenvolvimento e a saúde. Novos arranjos institucionais, como as alianças e coalizões com finalidades específicas, compostas de múltiplos parceiros, como o Fundo Global de Luta Contra Aids, Tuberculose e Malária (GLOBAL FUND, 2010) e a Aliança Global para Vacinas e Imunizações (GAVI, 2010), ao lado das fundações filantrópicas internacionais tradicionais, aportam recursos financeiros expressivos à saúde global, firmando-se mais como grandes provedores de assistência tradicional, do que como atores na cooperação inovadora em saúde. Países do sul em processo de crescimento e desenvolvimento mais acelerados, como Índia, China e Brasil tornaram-se provedores de auxílio e investidores internacionais; a União Européia acaba de lançar a iniciativa Global Health Europe (2010), definida como "uma plataforma para o engajamento da Europa em Saúde Global". Ao mesmo tempo, o número e o alcance das atividades de organizações da sociedade civil (OSC) cresceram, oferecendo suporte e serviços em todo o mundo. 
O Comitê de Saúde Global do Instituto de Medicina das Academias de Ciências dos Estados Unidos preparou dois documentos seminais sobre o 'Comprometimento dos Estados Unidos com a Saúde Global'; um deles, com recomendações à nova administração, entregue ao Presidente Obama logo após sua eleição (IOM, 2008a) e outro, o Relatório Final (IOM, 2008b), com recomendações sobre saúde global e cooperação internacional em saúde, ao governo e a sociedade americana em geral, bem como ao setor privado. Em fevereiro de 2010, em parte influenciado pelo informe do IOM, o governo americano lançou um documento de consulta sobre sua Iniciativa em Saúde Global (Global Health Initiative) (U.S. DEPARTMENT OF STATE, 2010), cujas bases repousam nitidamente nos princípios da Declaração de Paris e corrigem diversas deformações antes encontradas nos programas de ajuda para o desenvolvimento dos Estados Unidos.

Além disso, uma série de novos atores vem demonstrando o nível de comprometimento da sociedade civil com a cooperação internacional na saúde, incluindo a Federação Mundial de Associações de Saúde Pública (WFPHA, 2008), que reúne mais de 70 associações nacionais e regionais, e representa cerca de 250 mil profissionais da saúde pública em todo o mundo; e a Associação Internacional dos Institutos Nacionais de Saúde Pública (IANPHI, 2008; BUSS et al., 2009), que congrega cerca de 60 instituições já existentes e apóia institutos de saúde pública em países em desenvolvimento; entre muitos outros que se ocupam de diversos aspectos da saúde pública e assistência à saúde em todo o mundo.

Novas estratégias de financiamento e novos modelos de cooperação - assim como profundas mudanças em alguns países que transitaram para um nível intermediário de desenvolvimento e que agora são considerados 'Países Inovadores em Desenvolvimento' - estão facilitando novas parcerias para a saúde e, em consequência, para o desenvolvimento e, assim, para a paz. Entre eles encontrase o Brasil, cada vez mais presente na esfera internacional e na cooperação Sul-Sul em saúde (MRE, 2008; ALMEIDA et al., 2009). O país desenvolve um modelo de cooperação participativo, democrático, inclusivo e amplo, capaz de abrigar não apenas a dimensão da saúde, mas também seus determinantes sociais e políticas intersetoriais. Sustenta que a saúde é essencial para o desenvolvimento, que deve incluir a dimensão social, a cidadania, a qualidade de vida e a saúde, e não apenas o 'crescimento econômico'.

Ou seja, o balanço da cooperação internacional em saúde parece ser positivo, apesar da distância que frequentemente se identifica entre a grandiloquência da intenção e a materialização do gesto, sejam nas políticas de saúde global e diplomacia da saúde dos países, seja no âmbito das agências multilaterais ou, ainda, das OSC e parcerias globais.

Contudo, em que pese os sinais otimistas, os autores gostariam de explicitar sua profunda apreensão com a retração dos países mais ricos do mundo durante a presente crise financeira produzida por eles próprios, que poderia ameaçar a vital cooperação internacional em saúde. No entanto, se a comunidade global está disposta a empenhar trilhões de dólares para salvar bancos da bancarrota, também deve estar apta a alocar uma fração que seja para o combate à pobreza, à fome, às iniquidades e à exclusão social e para implementar projetos oportunos de cooperação internacional em saúde.

\section{Notas}

1. Uma fonte útil para o leitor interessado na avaliação da ajuda externa dos países desenvolvidos aos países em desenvolvimento é o site do Center for Global Development (http://www.cgdev.org) que, utilizando um indicador composto (Índice de Comprometimento com o Desenvolvimento/Commitment to Development Index) avalia diversas dimensões, como ajuda propriamente dita, comércio, investimentos, migração, ambiente, seguridade e tecnologia.

2. A análise da cooperação em Sul-Sul em saúde do Brasil é tema de artigo nesta mesma publicação (Almeida et al).

3. Buss e Ferreira (2010). Artigo sobre cooperação em saúde na UNASUL também pode ser encontrado em Buss (2009).

\section{Referências bibliográficas}

ALMEIDA C.; CAMPOS R. P.; BUSS P. M.; FERREIRA J. R.; FONSECA L. E. Brazil's conception of South-South 'structural cooperation in health', Innovating for the health for all, Global forum Update on Research for Health, v. 6, p. 199107, 2009.

BIRN A-E.; PILLAY Y.; HOLTZ T. H. International Health Agencies. In: Textbook of International Health. Oxford, 3r. ed., p.62-3. 2009.

BLOOM D. E. Governing global health. Finance \& Development, v.44, n.4, 2007. Disponível em: http:// www.imf.org/external/pubs/ft/fandd/2007/12/bloom.htm. Acessado em: 2 fev., 2010.

BROWN A. et al. The Status of Sector Wide Approaches. London: Overseas Development Institute, Working Paper, 142, 67 pp. 2001 
BUSS P.M. Globalization, poverty and health. J. Pub. Health Pol., v.28, p.2-25, 2007.

BUSS P.M. Global health and health diplomacy. J. Pub. Health Pol., v.29, p. 467-73, 2008.

BUSS P.M. A UNASUL Saúde. Le Monde Diplomatique Brasil, v.26, p.30-1, setembro de 2009.

BUSS P.M.; FERREIRA, J.R. Diplomacia da saúde e cooperação Sul-Sul: as experiências da Unasul Saúde e do Plano Estratégico de Cooperação em Saúde da CPLP. RECIIS v.4, n. 1, 2010.

BUSS P.M. et al. National Public Health Institutes: Their role in public health systems in Latin America. Pan American J Pub Health, v.26, n.2, p.184-8, 2009.

CASSELS, A. A guide to sector-wide approaches for health development. WHO: Geneva, 84 pp. Disponível em: http://www.eldis.org/go/topics/resource-guides/healthsystems/health-sector-financing/sector-wide-approachesswaps\&id=1 1508\&type=Document. Acessado em: 2 fev., 2010.

CONSÓRCIO DE UNIVERSIDADES PARA SAÚDE GLOBAL. 2010. Disponível em: www.cugh.org. Acessado em: 30 jan., 2010.

Consortium for Global Health Diplomacy (2010). Disponível em:http://graduateinstitute.ch/globalhealth/home/ page5058.html. Acessado em 30 jan., 2010.

CPLP. 2010. Disponível em: http://www.cplp.org. Acessado em: 30 jan., 2010.

ECONOMISTAS POR LA PAZ Y LA SEGURIDAD. Gastos militares vs. gastos sociales. Disponível em: http://wnw.eumed.net/ paz/tepys/gm-gs.htm. Acessado em: 22 dez., 2009.

FAO. World Summit on Food Security. 2009. Disponível em: http://www.fao.org/wsfs/world-summit/en. Acessado em: 22 dez., 2009.

FCTC. 2008. Disponível em: http://www.who.int/fctc/en. Acessado em: 19 fev., 2010.

FIOCRUZ 2010. Disponível em: http://www.fiocruz.br. Acessado em: 28 jan., 2010.

FOLHA ON LINE 2008. Disponível em: http://www1.folha.uol. com.br/folha/mundo/ult94u383146.shtml. Acessado em: 30 jan., 2010.

G77. Major documents. 2010. Disponível em: http://www.g77. org/doc/docs.html. Acessado em: 2 fev., 2010.
GARRET L. The challenge of global health. Foreign Affairs: January-February 2007. Disponível em: http://mww.google. com.br/search?sourceid=navclient\&ie=UTF-8\&rlz=1T4GGLR_ enBR302BR302\&q=laurie+garret+challenge+global+healht. Acessado em: 22 dez., 2009.

GAVI 2010. Disponível em: http://www.gavialliance.org. Acessado em: 30 jan., 2010.

GLOBAL FORUM FOR HEALTH RESEARCH. 2010. Disponível em: www.globalforumhealth.org. Acessado em 30 jan., 2010.

GLOBAL FUND. 2010. Disponível em: http://www. theglobalfund.org. Acessado em: 30 jan., 2010.

GLOBAL HEALTH EDUCATION CONSORTIUM. 2010. Disponível em: http://www.globalhealthedu.org. Acessado em: 30 jan., 2010.

GLOBAL HEALTH EUROPE. 2010. Disponível em: http://www. globalhealtheurope.org. Acessado em: 30 jan., 2010.

GOSTIN, L. O.; MOK E. A. Grand challenges in global health governance. Brit. Med. Bull., v.90, p.7-18, 2009.

HOBSBAWM, E. Age of Extremes: the short twentieth century (1914-1989). New York: Pantheon Books. 1995.

HUTTON, G.; TANNER M. The sector-wide approach: a blessing for public health? Bull. WHO, v.82, n.12, p. 893-4, 2004.

IANPHI. 2008. Disponível em: http://www.ianphi.org. Acessado em: 30 jan., 2010.

ILO/World Commission on the Social Dimension of Globalization. A fair globalization: creating opportunities for all. Geneva: International Labour Organization. 2004.

INTERNATIONAL HEALTH PARTNERSHIP - IHP e IHP. 2010. Disponível em: http://www.internationalhealthpartnership. net._Acessado em: 22 jan., 2010.

IOM. The U.S Commitment to Global Health: recommendations for the new administration.2008a. Disponível em: http://www.iom.edu/Reports/2008/TheUS-Commitment-to-Global-Health-Recommendations-forthe-New-Administration.aspx. Acessado em: 30 jan., 2010.

IOM. The U.S Commitment to Global Health: recommendations for the public and private sectors. 2008b. Disponível em: http://www.iom.edu/Reports/2009/TheUS-Commitment-to-Global-Health-Recommendations-forthe-Public-and-Private-Sectors.aspx. Acessado em: 30 jan., 2010.

IPCC. The Fourth Assessment Report (AR4). 2007. Disponível em: http://www.ipcc.ch/publications_and_data/ 
ar4/syr/en/contents.html. Acessado em: 8 fev., 2010

KICKBUSCH, I.; SILBERSCHMIDT, G.; BUSS, P. M. Global health diplomacy: the need for new perspectives, strategic approaches and skills in global health. Bull. WHO, v.85, n.3, p.230-2, 2007

MCKINSEY \& COMPANY. Global health partnerships: Assessing country consequences. 2005. Disponível em: http://www. hlfhealthmdgs.org/Documents/GatesGHPNov2005.pdf. Acessado em 28 set., 2009

MDG AFRICA STEERING COMMITTEE. Achieving the Millennium Development Goals in Africa. New York, 39 pp. 2008. Disponível em: http://www.mdgafrica.org/ pdf/MDGAfricaSteeringGroupRecommendations-EnglishHighRes.pdf. Acessado em 12 mai, 2009.

MINISTERS OF FOREIGN AFFAIRS OF BRAZIL, FRANCE, INDONESIA, NORWAY, SENEGAL, SOUTH AFRICA AND THAILAND. Oslo Ministerial Declaration - global health: a pressing foreign policy issue of our time. Lancet, v.369, p.1373-8, 2007.

MRE. Coordenação Geral de Cooperação Técnica entre Países em Desenvolvimento (CGPD). 2008. Disponível em: http://www.abc.gov.br/abc/abc_ctpd.asp. Acessado em: 19 jul., 2009.

NYERERE, J. Chairman's Preface. In: The Challenge to the South - The Report of the South Commission. New York: Oxford University Press, p. vii. 1990.

NYE, J. Public diplomacy and soft power. The Annals of The American Academy of Political and Social Science, v. 616, n. 1. p. 94-109, 2008.

OECD. Paris Declaration on Aids Effectiveness. 2005. Disponível em: http://uww.oecd.org/document/18/0,3343, en_2649_3236398_35401554_1_1_1_1,00.html. Acessado em: 19 set., 2009.

OECD. Survey on Monitoring the Paris Declaration. 2008. Disponível em: http://www.oecd.org/document/33/0,3343 ,en_21571361_39494699_39497377_1_1_1_1,00.html. Acessado em: 19 set., 2009.

OECD. Countries, Territories and Organizations adhering to the Paris Declaration. 2009. Disponível em:http://www.oecd.org/document/22/0,3343, en_2649_3236398_36074966_1_1_1_1,00.html. Acessado em: 19 set., 2009.

OXFAM. Paying the price: why rich countries must invest now in a war against poverty. Disponível em: http://www. oxfam.org.uk/what_we_do/issues/debt_aid/downloads/ mdgs_price_summ.pdf. Acessado em: 2 set., 2005.

RØTTINGEN, J. A.; BUSS, P. M.; DAVIES, S.; TOURÉ, O. Globalhealth research architecture - time for mergers? Lancet, v.373, n.9659, p.193-5, January, 2009.

TDR/OMS. Tropical Diseases Reasearch Program. 2010. Disponível em: http://apps.who.int/tdr. Acessado em: 30 jan., 2010

THE SOUTH COMMISSION. The Challenge to the South - The report of the South Commission. New York: Oxford University Press, 325 pp. 1990.

UN-UNITED NATIONS. The Millennium Development Goals Report. 2000. Disponível em: http://www.un.org/ millenniumgoals. Acessado em: 22 dez., 2009.

UN-UNITED NATIONS. The Millennium Development Goals Report. 2007. Disponível em: http://www.un.org/ millenniumgoals/2008highlevel/pdf/newsroom/mdg\%20 reports/MDG_Report_2007_ENGLISH.pdf. Acessado em: 22 dez., 2009.

UN-UNITED NATIONS. The Millennium Development Goals Report. 2008. Disponível em: http://www.un.org/ millenniumgoals/2008highlevel/pdf/newsroom/mdg\%20 reports/MDG_Report_2008_ENGLISH.pdf. Acessado em: 22 dez., 2009.

UN-UNITED NATIONS. $3^{\text {rd. }}$ High Level Forum on Aids Effectiveness: The Accra Agenda for Action. 2008a. Disponível em: http://www.oecd.org/document/3/0,3 343,en_2649_3236398_41297219_1_1_1_1,00.html Acessado em: 23 dez., 2009.

UN-UNITED NATIONS. International Conference on Financing for Development: Doha Declaration on Financing for Development 2008b. Disponível em: http://www.un.org/ esa/ffd/doha. Acessado em: 23 dez., 2009.

UN-UNITED NATIONS. Endpoverty 2015. Hight level event,http://www.un.org/milleniungoals/2008highlevel/. Acessado em: 15 fev., 2010.

UN-UNITED NATIONS. Conference on South-South Cooperation 2009. Disponível em: http://southsouthconference. org. Acessado em: 2 fev., 2010.

UN/ECOSOC. 2009. Disponível em: http://www.un.org/en/ ecosoc/julyhls/index.shtml. Acessado em: 30 jan., 2010. 
UNASUL SALUD. 2009. Disponível em: http://www.unasursalud.org. Acessado em: 28 fev. , 2010.

UNDP. United Nations Conference on Technical Cooperation among Developing Countries. The Buenos Aires Plan of Action. 1978. Disponível em: http://tcdc.undp. org/knowledge_base/bapa_english 1.html. Acessado em: 28 dez., 2009.

UNDP. Forging a global South. 2004.Disponível em: http:// tcdc.undp.org/TDCDpubl.asp. Acessado em: 28 dez., 2009.

U.S. DEPARTMENT OF STATE. 2010. Global health Initiative Consultation Document. Disponível em: http://www.state. gov/headlines/136365.htm. Acessado em: 2 fev., 2010.

WALDORF, V. A review of health sector wide approaches in Africa. London: HLSP Institute, 30pp. 2007.

WFPHA (2008). Disponível em: http://www.wfpha.org . Acessado em: 26 jun., 2008.

WHO-WORLD HEALTH ORGANIZATION. The World Health Report 2006: Working together for health. Genève: WHO, 201 pp. 2006a. Disponível em: http://www.who.int/whr/2006/en. Acessado em: 19 out., 2009.

WHO-WORLD HEALTH ORGANIZATION. Global Health Workforce Alliance: Estrategic Plan. 2006.Geneve: WHO, 43 pp. Disponível em: http://www.who.int/workforcealliance. Acessado em: 19 out., 2009.

WHO-WORLD HEALTH ORGANIZATION. 2008a. The World Health Report 2008: primary health care, now more than ever. Genève: WHO, 119 pp. Disponível em: http://www.who. int/whr/2008/en. Acessado em: 19 out., 2009.
WHO-WORLD HEALTH ORGANIZATION. 2008b. Closing the gap in a generation - Commission on Social Determinants of Health Final Report Genève: WHO, 246 pp. Disponível em: http://www.who.int/social_determinants/final_report/en. Acessado em: 19 out., 2009.

WHO-WORLD HEALTH ORGANIZATION. 2009a. World Health Statistics 2009. Disponível em: http://www.who.int/pmnch/ topics/add_publications/2009_whostats/en. Acessado em: 19 out., 2009.

WHO-WORLD HEALTH ORGANIZATION. Resolution WHA62.14. 2009b.Disponível em: http://apps.who.int/gb/ e/e_wha62.html\#Resolutions. Acessado em: 19 out., 2009.

WHO-WORLD HEALTH ORGANIZATION. International recruitment of health personnel: draft global code of practice. Executive Board, 124 $4^{\text {th }}$ Session, doc. EB 124/13. 2009c. Disponível em: http://www.who.int/gb/ebwha/pdf_ files/EB124/B124_13-en.pdf. Acesso em: 19 out., 2009.

WHO-WORLD HEALTH ORGANIZATION. Country focus 2010. Disponível em: http://www.who.int/countryfocus/en. Acessado em: 15 fev., 2010.

WHO AFRO. The health of the people - The African regional health report. Brazzaville: WHO AFRO, 170 pp. 2006. Disponível em: http://www.afro.who.int/regionaldirector/ african_regional_health_report2006.pdf. Acessado em: 19 out., 2009.

WORD BANK (2008). Global Monitoring Report 2008. Available at: http://web. worldbank.org/wbsite/external/ extdec/extglobalmonitor/extglomonrep2008/0,menupk:47 38069 pagepk:64168435 thesitepk:4738057,00.h 